\title{
Are Australian clinicians monitoring medication adherence in hematological cancer survivors? Two cross-sectional studies
}

Marita C. Lynagh ${ }^{*}$, Tara Clinton-McHarg ${ }^{2}$, Alix Hall ${ }^{1}$, Rob Sanson-Fisher ${ }^{1}$, William Stevenson ${ }^{3}$, Campbell Tiley ${ }^{1}$ and Alessandra Bisquera ${ }^{4}$

\begin{abstract}
Background: Hematological cancer survivors are growing in number and increasingly rely on oral therapy. Given known poor outcomes associated with non-adherence and previous evidence that many patients do not fully adhere to their treatment regimen, this study aimed to determine the degree to which clinicians monitor adherence to oral medication in hematological cancer survivors.

Methods: Data was combined from two cross-sectional surveys of a heterogeneous sample of 431 hematological cancer survivors recruited from three outpatient hematology clinics in three different states $(n=215)$ and one state cancer registry $(n=216)$ in Australia. Participants completed a self-administered survey that included demographic characteristics and a 7-item measure of medication adherence developed by the researchers specifically for the purpose of the studies.

Results: Of the 431 participants, $37 \%(n=160)$ reported currently taking daily cancer-related medication. Of these, $14 \%(n=23)$ were found to be non-adherent with 'missing a dose' being the most commonly reported non-adherent behaviour. Only $41 \%$ of survivors indicated that their hematologist or cancer clinician had 'always' asked about their cancer-related medication during their last six visits.

Conclusions: Non-adherence to oral therapy remains a problem in hematological cancer survivors, yet clinicians in Australia do not appear to be regularly monitoring adherence in their patients. Given an increasing dependence on oral therapy in clinical hematology and medical oncology and the importance of medication adherence to optimising health outcomes, greater effort should be invested in developing effective interventions to improve support and adherence monitoring by cancer clinicians and GPS.
\end{abstract}

Keywords: Medication adherence, Hematological cancer, Oral therapy

\section{Background}

Patient non-adherence to medication is a well-recognised problem in all cancer populations [1], including among hematological cancer patients [2]. Recent findings from three different studies on adherence to imatinib oral therapy in Chronic Myeloid Leukaemia (CML) patients confirm this phenomenon [3-5]. The proportion of patients not adhering to medication is estimated to be $25 \%$ using

\footnotetext{
* Correspondence: Marita.Lynagh@newcastle.edu.au

${ }^{1}$ School of Medicine and Public Health, Faculty of Health and Medicine, University of Newcastle, Level 4, West, HMRI Building, Callaghan, NSW 2308, Australia

Full list of author information is available at the end of the article
}

pharmacy and medical claims data [3], $36 \%$ using self-report and pill counts [4] and $2 \%$ using MEMS (microelectronic monitoring devices) [5]. Despite median non-adherence rates being low, Marin and colleagues found that $26 \%$ of patients were less than $90 \%$ adherent and $14 \%$ of patients were less than $80 \%$ adherent [5].

Poor medication adherence among hematological cancer patients plays a significant role in treatment failure [6] and survival [7]. For example, patients with lower imatinib adherence rates have poorer responses to therapy (such as loss of cytogenetic responses) and higher medical costs [3-5]. Given that: 1) the number of hematological cancer survivors is growing [8];2) complex and lengthy treatment 
regimens [9] are becoming increasingly reliant on oral therapy; and 3) serious adverse outcomes have been associated with poor drug adherence, regular assessment of medication adherence by health care providers in this population is critical.

To date, a range of factors involving the patient, their disease characteristics, clinicians and the health care system $[10,11]$ have been found to impact on medication adherence. These factors include: treatment side effects [10, 12]; poor patient-doctor relationship [13]; and medication costs [13]. Patients who lack knowledge about the side-effects and benefits of medication [14]: feel less control over their health care [15]; dislike aspects of their medication [15]; have a poorer disease prognosis [16]; and perceive inadequacies in their health care delivery [16], are also less likely to adhere. Having insight into these factors may assist clinicians in recognising patients who may be at greater risk of not adhering to oral therapy.

While disease progression, complications or lack of response to therapy may all be signs of poor adherence, these may nevertheless be absent in a patient who is not taking oral medication as prescribed. A key component to improving medication adherence is follow-up and support [17]. Patients should be regularly asked, in a non-judgmental way, about their use of medications by their clinicians [10, 17]. However, a review of the field has found no studies to date which have investigated the degree to which clinicians ask cancer survivors about their adherence to oral therapy.

Further, although hematological cancer survivors are a diverse group, the few studies investigating medication adherence published to date have focussed predominantly on adherence in CML patients only and report wide variations in adherence rates [3-5]. There remains a vital need to investigate the problem of medication non-adherence in more heterogeneous hematological cancer populations to identify the most common patterns of non-adherence behaviours and better understand clinician practice so that effective strategies can be employed to improve adherence among survivors.

The purpose of this study was to assess self-reported medication adherence by hematological cancer survivors and perceived clinician behaviour in relation to monitoring of their oral therapy adherence. Specifically, it aimed to:

1. Identify the proportion of hematological cancer survivors in Australia who report non-adherence to medication;

2. Describe the frequency with which Australian cancer survivors report being asked about their medication adherence by their hematologists or cancer doctors, and their general practitioners (GPs) or family doctors;
3. Identify demographic and disease characteristics of survivors associated with infrequent medication adherence monitoring by clinicians.

\section{Method}

\section{Study design \& setting}

The study combined data from two independent crosssectional surveys of adult hematological cancer survivors. In one study, survivors were recruited from three outpatient hematology treatment clinics in three different Australia states, while the second study recruited survivors from one state cancer registry in a fourth Australian state. For both studies, the data presented here on medication adherence was one component of a much larger national study on the unmet needs of haematological cancer survivors.

\section{Sample and procedure}

Eligible participants were aged 18 years or older at time of the studies, could read and understand English, and had a confirmed diagnosis of hematological cancer. For registry-recruited participants, diagnosis was within the last 3 years.

At treatment clinics, a hematologist or nurse first identified potentially eligible patients who were then approached by a research assistant and invited to take part in the study from October 2012 to March 2013. Consenting patients were asked to complete two pen and paper questionnaires, one in the clinic while waiting for their appointment (which included demographic and disease characteristics) and a second questionnaire one month later that was posted to their home address (containing the medication adherence questions). One written reminder was sent to patients who had not returned their completed survey within two weeks of consenting to participate. Three hundred and ninety-five (395) patients were identified as eligible and approached to participate in the study, and 353 (89\%) consented to participate.

A rolling recruitment method was utilised at the cancer registry. Eligible survivors were identified and approached on an on-going basis between September 2012 and September 2013. Active clinician consent was employed as the standard patient recruitment procedure by this registry. This meant that consent was first required from the treating clinician before the registry contacted their patients. Contacted patients were asked if they agreed to have their contact details released by the registry to the researchers. Participants who consented to having their contact details released were sent a self-administered pen-and-paper questionnaire. Nonresponders were mailed a second copy of the survey approximately four weeks later. There were 1480 hematological cancer survivors identified as eligible for the study. Clinicians consented to the registry 
contacting 616 of these, with missing registry data, clinician non-response and deceased participants being the main reasons for clinician non-consent. Of the 616 survivors approached by the registry, 316 (51\%) consented to having their contact details forwarded to the researchers.

Ethics approval was obtained from the University of Newcastle Human Research Ethics Committee and the relevant ethics committees associated with each of the treatment clinics and the cancer registry.

\section{Measures}

Participants completed a self-administered questionnaire that included questions about demographic characteristics (eg. marital status, education level, employment status) and cancer history and treatment. For participants recruited via the cancer registry, some demographic and disease characteristics (eg. sex, postcode, country of birth, cancer type) were obtained directly from the cancer registry's records.

Participants also completed seven items assessing medication adherence and perceived clinician behaviour that were developed by the research team in close consultation with hematologists and oncologists. Relevant medication adherence behaviours were first identified from a review of the literature, checked against behaviours reported as important by clinicians, and then arranged into a draft questionnaire. The draft questionnaire was sent to three hematologists in Australia and three international experts in the field of medication adherence for review. Any possible missing medication adherence behaviours identified by the experts were then added to the questionnaire. Item wording and response options were also refined. A copy of the final seven items used can be seen in Table 1.

\section{Statistical analysis}

For the purpose of this study, 'non-adherence' was defined as reporting at least one of the four behaviour patterns associated with non-adherent behaviour (items 2 to 5 in Table 1). Statistical analysis was undertaken using SAS version 9.4 (SAS Institute Inc, Cary, NC). For each of the seven items assessing adherence and clinician behaviours, the frequency and percentage of responses were calculated to identify the proportion of hematological cancer survivors who reported non-adherence to medication, and the frequency with which cancer survivors report being asked about their medication adherence by their hematologists or their general practitioners (GP)/family doctors. Fisher's exact analyses were used to compare medication adherence behaviour by sex, age, rural versus urban geographical location and cancer type. Rural versus urban location was defined using postcode at diagnosis, based on the Australian Bureau of Statistics (ABS) five
Table 1 Seven items assessing Medication Adherence \& Clinician Behaviour

\begin{tabular}{|c|c|}
\hline \multicolumn{2}{|c|}{$\begin{array}{l}\text { Thinking about the prescribed medications you are taking related } \\
\text { to your cancer or treatment side-effects: }\end{array}$} \\
\hline $\begin{array}{l}\text { 1. How many different prescribed medications related } \\
\text { to your cancer or treatment side-effects are you } \\
\text { currently taking EACH DAY? }\end{array}$ & $\begin{array}{l}\mathrm{Nil} / 1-2 / 3-4 / \\
5-6 / 7-8 / 9 \\
\text { or more }\end{array}$ \\
\hline $\begin{array}{l}\text { 2. In the last } 7 \text { days, have you missed a dose of } \\
\text { one or more of your medications? }\end{array}$ & No Yes \\
\hline $\begin{array}{l}\text { 3. In the last } 7 \text { days, have you taken a medication } \\
\text { at the wrong time? (eg. taken the medication } \\
\text { at lunchtime instead of with breakfast) }\end{array}$ & No Yes \\
\hline $\begin{array}{l}\text { 4. In the last } 7 \text { days, have you taken a higher } \\
\text { dose of a medication than as prescribed? }\end{array}$ & No Yes \\
\hline $\begin{array}{l}\text { 5. In the last } 6 \text { months, have you stopped taking any } \\
\text { prescribed cancer-related medications without } \\
\text { first getting your doctor's approval to do so? }\end{array}$ & No Not sure Yes \\
\hline \multirow{4}{*}{$\begin{array}{l}\text { 6. At your last } 6 \text { visits to your hematologist or cancer } \\
\text { doctor, on how many of these occasions did they } \\
\text { ask you whether you have been taking your } \\
\text { cancer-related medications as prescribed? }\end{array}$} & $\begin{array}{l}\text { Always, at every } \\
\text { appointment }\end{array}$ \\
\hline & $\begin{array}{l}\text { Sometimes, but } \\
\text { not at every } \\
\text { appointment }\end{array}$ \\
\hline & Never \\
\hline & $\begin{array}{l}\text { Not sure / can't } \\
\text { remember }\end{array}$ \\
\hline \multirow{4}{*}{$\begin{array}{l}\text { 7. At your last } 6 \text { visits to your GP or regular doctor, } \\
\text { on how many of these occasions did they ask } \\
\text { you whether you have been taking your } \\
\text { cancer-related medications as prescribed? }\end{array}$} & $\begin{array}{l}\text { Always, at every } \\
\text { appointment }\end{array}$ \\
\hline & $\begin{array}{l}\text { Sometimes, } \\
\text { but not at every } \\
\text { appointment }\end{array}$ \\
\hline & Never \\
\hline & $\begin{array}{l}\text { Not sure / can't } \\
\text { remember }\end{array}$ \\
\hline
\end{tabular}

categories of the Accessibility and Remoteness Index of Australia (ARIA+) classification [18]. Participants whose postcodes fell within the ABS categories of major cities of Australia and inner regional were classified as 'urban'. Those with postcodes falling within the categories of outer regional, remote and very remote Australia were defined as 'rural'. Fisher's exact test was also used to identify demographic and disease characteristics associated with infrequent medication adherence monitoring by clinicians. While sample size estimates were not calculated for the sub-studies presented, both of the larger studies from which they derived were estimated to permit statistical analyses with a power of $80 \%$ and a significance level of $5 \%$ in relation to the main outcome measures.

\section{Results}

\section{Participants}

Two hundred and fifteen patients attending outpatient hematological treatment centres and 216 hematological cancer survivors recruited through the cancer registry completed survey items pertaining to medication adherence (total $n=431$ ), representing participation rates of 
$54 \%$ and $42 \%$ respectively. Of these, 160 participants (37\%) reported taking at least one medication each day related to their cancer diagnosis or treatment sideeffects. The majority of participants were males (55\%) and only $3 \%$ of participants were aged less than 40 years (see Table 2). The most common cancer type was myeloma (38 \%). Participants recruited through treatment centres differed from those recruited via the cancer registry in regard to usual residence $(p<0.0001)$ and time since diagnosis $(p<0.0001)$ with treatment centre participants more likely to live in urban areas and be less than 2 years post-diagnosis compared with registryrecruited cancer survivors. Participants differed from non-participants in regard to age $(p=0.0007)$ with fewer participants aged below 50 years and cancer type $(p=0.029)$ with higher proportions of participants with NHL and myeloma and a lower proportion of Hodgkin lymphoma cancer patients. The study samples did not differ from non-participants by sex or usual residence.
The 160 participants who reported taking daily medication differed from non-medication participants in time since diagnosis $(p<0.0001)$ with medicated participants more likely to be diagnosed less than 2 years prior, and by cancer type $(p<0.0001)$ with higher proportions of participants with acute leukaemia and myeloma reporting taking cancer-related medications every day.

\section{Medication non-adherence behaviour of hematological cancer survivors}

Of the 160 participants taking daily medications, almost a quarter $(24 \%, n=38)$ were taking five or more medications each day (see Fig. 1). Eighty-six percent of participants prescribed oral therapy were found to be adherent, with $14 \%(n=23)$ defined as 'non-adherent' according to the study criteria. The most commonly reported nonadherent behaviour was missing a dose $(9 \%, n=15)$ with very few participants failing to take their medication at the correct time $(3 \%, n=4)$ or ceasing a medication without

Table 2 Demographic and disease characteristics of participants ${ }^{\mathrm{a}}$

\begin{tabular}{|c|c|c|c|c|c|}
\hline \multicolumn{2}{|l|}{ Characteristic } & \multirow{2}{*}{$\begin{array}{l}\text { Cancer Registry participants } \\
(N=62) \\
n(\%)\end{array}$} & \multirow{2}{*}{$\begin{array}{l}\text { Treatment Centre participants } \\
(N=98) \\
n(\%)\end{array}$} & \multirow{2}{*}{$\begin{array}{l}\text { Total }(N=160) \\
n(\%)\end{array}$} & \multirow[t]{2}{*}{ Exact $p$-value } \\
\hline \multirow{3}{*}{$\mathrm{Sex}^{\mathrm{b}}$} & & & & & \\
\hline & Male & $26(49 \%)$ & $57(58 \%)$ & $83(55 \%)$ & 0.307 \\
\hline & Female & $27(51 \%)$ & $41(42 \%)$ & $68(45 \%)$ & \\
\hline \multirow[t]{5}{*}{$\mathrm{Age}^{\mathrm{b}}$} & $18-39$ years & $1(2 \%)$ & $4(4 \%)$ & $5(3 \%)$ & 0.658 \\
\hline & $40-49$ years & $5(9.4 \%)$ & $7(7 \%)$ & $12(8 \%)$ & \\
\hline & $50-59$ years & $18(34 \%)$ & $25(26 \%)$ & $43(28 \%)$ & \\
\hline & $60-69$ years & $12(23 \%)$ & $31(32 \%)$ & $43(28 \%)$ & \\
\hline & 70 years and over & $17(32 \%)$ & $31(32 \%)$ & $48(32 \%)$ & \\
\hline \multirow[t]{6}{*}{ Cancer type ${ }^{b}$} & Non-Hodgkin Lymphoma (NHL) & $20(38 \%)$ & $18(18 \%)$ & $38(25 \%)$ & 0.051 \\
\hline & Acute Leukaemia (AL) & $8(15 \%)$ & $11(11 \%)$ & $19(13 \%)$ & \\
\hline & Chronic Lymph Leukaemia (CLL) & $3(6 \%)$ & $11(11 \%)$ & $14(9 \%)$ & \\
\hline & Myeloma & 19 (36 \%) & $39(40 \%)$ & $58(38 \%)$ & \\
\hline & Hodgkin Lymphoma (HL) & $1(2 \%)$ & $6(6 \%)$ & $7(5 \%)$ & \\
\hline & Other & $2(4 \%)$ & $13(13 \%)$ & $15(10 \%)$ & \\
\hline \multirow[t]{2}{*}{ Usual residence ${ }^{b}$} & Urban & $30(57 \%)$ & $95(97 \%)$ & $125(83 \%)$ & $<0.0001$ \\
\hline & Rural & $23(43 \%)$ & $3(3 \%)$ & $26(17 \%)$ & \\
\hline \multirow[t]{2}{*}{ Time since diagnosis $^{\mathrm{b}}$} & Less than 2 years & - & $52(53 \%)$ & $52(34 \%)$ & $<0.0001$ \\
\hline & 2 years and over & $53(100 \%)$ & $46(47 \%)$ & $99(66 \%)$ & \\
\hline \multirow[t]{2}{*}{ Marital status ${ }^{b}$} & Married/living with partner & $51(84 \%)$ & $71(74 \%)$ & $122(78 \%)$ & 0.174 \\
\hline & Single, never married & $10(16 \%)$ & $25(26 \%)$ & $35(22 \%)$ & \\
\hline \multirow[t]{3}{*}{ Education ${ }^{\mathrm{b}}$} & High school or below & $28(48 \%)$ & $45(50 \%)$ & $73(49 \%)$ & 0.818 \\
\hline & Trade or TAFE & $15(26 \%)$ & $26(29 \%)$ & $41(28 \%)$ & \\
\hline & University degree & $15(26 \%)$ & $19(21 \%)$ & $34(23 \%)$ & \\
\hline \multirow[t]{2}{*}{ Employment ${ }^{\mathrm{b}}$} & Currently employed & $23(38 \%)$ & $32(33 \%)$ & $55(35 \%)$ & 0.607 \\
\hline & Not employed & $38(62 \%)$ & $66(67 \%)$ & $104(65 \%)$ & \\
\hline
\end{tabular}

aparticipants are those who reported currently taking daily cancer-related medications

${ }^{\mathrm{b}}$ Totals may not equal sample size due to missing data values 




Fig. 1 Number of daily prescribed cancer-related medications reported by hematological cancer survivors recruited for each study

their doctor's approval $(3 \%, n=4)$ (see Table 3). Usual residence was significantly associated with non-adherence behaviour with urban participants more likely to be nonadherent compared with rural $(p<0.007)$. The only other factor significantly associated with non-adherence was age with those aged less than 40 years more likely to report non-adherence behaviours $(p<0.039)$.

\section{Monitoring of medication adherence by clinicians}

Among hematological cancer survivors on daily oral therapy, only $41 \%$ indicated that their hematologist or cancer doctor 'always' asked whether they had been taking their prescribed cancer-related medications during their last six visits. Almost a quarter $(23 \%, n=37)$ of participants reported that they were 'never' asked about their medications. A high proportion of participants (40\%) also indicated that they were never asked whether they had been taking their prescribed cancer-related medications by their GP or regular doctor during the last six visits, with only $29 \%$ reporting being 'always' questioned about cancer-related medications by their GP (see Table 4). There was no significant difference in adherence behavior between participants who reported "always" being asked by their hematologist or their GP about medications compared to those who reported that they were asked only "sometimes" or "never" $(p=0.072)$.

Factors associated with clinician monitoring of adherence For both hematologists and regular GPs, no significant differences were found between cancer survivors who were 'always' asked about taking their cancer-related medication and those who were not, in relation to the survivors' gender, age, cancer type, time since diagnosis, marital status, education level and number of medications taken per day (see Table 5).

Table 3 Medication non-adherence behaviour in hematological cancer survivors

\begin{tabular}{|c|c|c|}
\hline \multirow[b]{2}{*}{ Medication non-adherence behaviours } & \multicolumn{2}{|c|}{ Participants $(N=160)$} \\
\hline & $\mathrm{N}$ & $\%$ \\
\hline Missed a dose of 1 or more medications in last 7 days & 15 & 9 \\
\hline Did not take a medication at the correct time prescribed in last 7 days & 4 & 3 \\
\hline Took a higher dose of medication than prescribed in last 7 days & 3 & 2 \\
\hline Stopped taking a prescribed medication without first getting doctor's approval in last 6 months & 4 & 3 \\
\hline Reported at least 1 or more medication non-adherence behaviour & $23^{\mathrm{a}}$ & 14 \\
\hline
\end{tabular}

${ }^{a}$ Some participants reported more than one behaviour 
Table 4 Clinician assessment of medication adherence in hematological cancer survivors $(N=160)$

\begin{tabular}{|c|c|c|c|c|}
\hline Clinician behaviour & Always N (\%) & Sometimes N (\%) & Never N (\%) & $\begin{array}{l}\text { Not sure/can't } \\
\text { remember } N(\%)\end{array}$ \\
\hline $\begin{array}{l}\text { Hematologist or cancer doctor asked whether you have been taking } \\
\text { cancer-related medications as prescribed during last } 6 \text { visits }^{a}\end{array}$ & $64(41 \%)$ & $48(30 \%)$ & $37(23 \%)$ & $9(6 \%)$ \\
\hline $\begin{array}{l}\text { GP or regular doctor asked whether you have been taking cancer-related } \\
\text { medications as prescribed during last } 6 \text { visits }{ }^{\mathrm{b}}\end{array}$ & $45(29 \%)$ & $42(27 \%)$ & $63(40 \%)$ & $7(4 \%)$ \\
\hline
\end{tabular}

${ }^{\mathrm{a} M i s s i n g}$ data $n=2$

${ }^{\mathrm{b}}$ Missing data $n=3$

\section{Discussion}

Although many hematological cancers require long-term management [9], this study found that only $37 \%$ of participants were taking daily medication related to their cancer or side-effects of treatment. As a significant proportion of participants had been diagnosed more than two years prior to the survey, it is likely that some may have completed treatment and/or were in the 'watchful waiting' stage of survivorship [19].

Of the 160 survivors who were currently prescribed oral therapy, the majority ( $86 \%$ ) were found to be adherent. While this provides evidence that medication non-adherence among hematological cancer survivors occurs, it suggests that the problem may not be as

Table 5 Associations between patient characteristics and clinician monitoring of medication adherence

\begin{tabular}{|c|c|c|c|c|c|c|c|}
\hline \multirow{2}{*}{ Characteristic } & & \multicolumn{3}{|c|}{ Monitoring by Hematologist } & \multicolumn{3}{|c|}{ Monitoring by GP or regular doctor } \\
\hline & & $\begin{array}{l}\text { Always } \\
(n=64) \\
n(\%)\end{array}$ & $\begin{array}{l}\text { Sometimes or } \\
\text { never }(n=94) \\
n(\%)\end{array}$ & Exact $p$ value & $\begin{array}{l}\text { Always } \\
(n=45) \\
n(\%)\end{array}$ & $\begin{array}{l}\text { Sometimes or } \\
\text { never }(n=112) \\
n(\%)\end{array}$ & Exact $p$-value \\
\hline \multirow[t]{2}{*}{$\operatorname{Sex}^{a}$} & Male & $30(48 \%)$ & $52(60 \%)$ & 0.185 & $21(48 \%)$ & $61(59 \%)$ & 0.278 \\
\hline & Female & $32(52 \%)$ & $35(40 \%)$ & & $23(52 \%)$ & $43(41 \%)$ & \\
\hline \multirow[t]{5}{*}{$\mathrm{Age}^{\mathrm{a}}$} & $18-39$ years & $2(3.2 \%)$ & $3(3.4 \%)$ & 0.655 & $2(4.5 \%)$ & $3(2.9 \%)$ & 0.878 \\
\hline & $40-49$ years & $7(11 \%)$ & $5(5.7 \%)$ & & $4(9 \%)$ & $8(7.7 \%)$ & \\
\hline & $50-59$ years & $19(31 \%)$ & $24(28 \%)$ & & $14(32 \%)$ & $28(27 \%)$ & \\
\hline & $60-69$ years & $18(29 \%)$ & $25(29 \%)$ & & $12(27 \%)$ & $30(29 \%)$ & \\
\hline & 70 years and over & $16(26 \%)$ & $30(34 \%)$ & & $12(27 \%)$ & $35(34 \%)$ & \\
\hline \multirow[t]{6}{*}{ Cancer type $e^{a}$} & Non-Hodgkin Lymphoma & $16(26 \%)$ & $21(24 \%)$ & 0.599 & $14(32 \%)$ & $22(21 \%)$ & 0.253 \\
\hline & Acute Leukaemia & $7(11 \%)$ & $12(14 \%)$ & & $3(6.8 \%)$ & $16(15 \%)$ & \\
\hline & Chronic Lymph Leukaemia & $7911 \%)$ & $7(8 \%)$ & & $3(6.8 \%)$ & $11(11 \%)$ & \\
\hline & Myeloma & $22(35 \%)$ & $35(40 \%)$ & & $17(39 \%)$ & $40(38 \%)$ & \\
\hline & Hodgkin Lymphoma & $5(8 \%)$ & $2(2.3 \%)$ & & $4(9 \%)$ & $3(2.9 \%)$ & \\
\hline & Other & $5(8 \%)$ & $10(11 \%)$ & & $3(6.8 \%)$ & $12(12 \%)$ & \\
\hline \multirow[t]{2}{*}{ Usual residence $^{a}$} & Urban & $52(84 \%)$ & $72(83 \%)$ & 1.000 & $37(84 \%)$ & $86(83 \%)$ & 1.000 \\
\hline & Rural & $10(16 \%)$ & $15(17 \%)$ & & $7(16 \%)$ & $18(17 \%)$ & \\
\hline \multirow[t]{2}{*}{ Time since diagnosis ${ }^{\mathrm{a}}$} & Less than 2 years & $24(39 \%)$ & $28(32 \%)$ & 0.486 & $20(45 \%)$ & $31(30 \%)$ & 0.088 \\
\hline & 2 years and over & $38(61 \%)$ & $59(68 \%)$ & & $24(55 \%)$ & $73 \%(70 \%)$ & \\
\hline \multirow[t]{2}{*}{ Marital status ${ }^{\mathrm{a}}$} & Married/living with partner & $17(27 \%)$ & $18(20 \%)$ & 0.336 & $13(29 \%)$ & $22(20 \%)$ & 0.291 \\
\hline & Single, never married & $47(73 \%)$ & $73(80 \%)$ & & $32(71 \%)$ & $87(80 \%)$ & \\
\hline \multirow[t]{3}{*}{ Education $^{a}$} & High school or below & $27(45 \%)$ & $44(51 \%)$ & 0.309 & 19 (46 \%) & $53(51 \%)$ & 0.786 \\
\hline & Trade or TAFE & $21(35 \%)$ & $20(23 \%)$ & & $13(32 \%)$ & $27(26 \%)$ & \\
\hline & University degree & $12(20 \%)$ & $22(26 \%)$ & & $9(22 \%)$ & $24(23 \%)$ & \\
\hline \multirow[t]{2}{*}{ Employment $^{\mathrm{a}}$} & Currently employed & $23(36 \%)$ & $32(34 \%)$ & 0.866 & $16(36 \%)$ & $38(34 \%)$ & 1.000 \\
\hline & Not employed & $41(64 \%)$ & $61(66 \%)$ & & $29(64 \%)$ & $73(66 \%)$ & \\
\hline \multirow[t]{2}{*}{ No. of daily medications } & 2 or less & 31 (48 \%) & 46 (49 \%) & 1.000 & $21(47 \%)$ & $56(50 \%)$ & 0.727 \\
\hline & 3 or more & 33 (52 \%) & 48 (51 \%) & & $24(53 \%)$ & 56 (50 \%) & \\
\hline
\end{tabular}

${ }^{a}$ Totals may not equal sample size due to missing data values 
extensive as previous research has indicated [11]. Our self-reported non-adherence rate of $14 \%$ is less than the $36 \%$ found by Noens et al. [4] but greater than the $9 \%$ reported in the findings of the IRIS trial (International Randomized Study of Interferon versus ST1571) [20]. The difference in reported non-adherence rates could be due to the fact that previous studies had investigated only CML patients in contrast to the present study which included all major hematological cancers. Further, it is likely that the $9 \%$ non-adherence rate reported in the IRIS clinical trial [2] was due to the close surveillance and greater assessment frequency of patients involved in a clinical trial compared to "real world" patient populations.

The most commonly reported non-adherent behaviour in the current study was missing a dose, consistent with broader findings relating to medication adherence for general health care [21]. However, we were not able to determine whether this behaviour was unintentional (ie. simply forgetting) or a deliberate choice to not take a medication. Previous research has suggested that few cancer patients intentionally choose to miss a dose [15]. Participants were further not asked to distinguish between oral cancer medications and medications taken to prevent or manage treatment side effects, hence it is possible that when a dose is missed, this could relate to medications for side-effects.

To our knowledge, this study was the first to examine clinician behaviour in relation to monitoring medication adherence in hematological cancer survivors. Only $41 \%$ of survivors (currently taking oral therapy) reported being always asked about their medications by their cancer doctor, with most participants indicating that they were never or only 'sometimes' prompted by either their hematologist or regular clinician to discuss their cancerrelated medications. Even though survivor self-report was used as a proxy measure for actual clinician behaviour, the perceived low frequency of clinician-initiated questions regarding medications may be interpreted by cancer survivors to mean that medications and adherence to a prescribed schedule are not important to their prognosis. Given evidence that patients' beliefs about the costs and benefits of oral therapy is a strong predictor of adherence [22, 23], further research is needed to investigate the actions of clinicians and their role in guiding survivors' beliefs about the risk-benefit ratio. Clinicians themselves acknowledge the critical role they play in patient education [4] and endorse the routine assessment of adherence behaviour in hematological cancer survivors $[4,10]$. The perceived poor assessment of medication adherence by clinicians may reflect an assumption on the clinician's behalf that patients are fully adherent or a belief that survivors with a longer time since diagnosis may have already developed a good understanding of the importance of taking their medication.

\section{Strengths and limitations}

This study investigated a diverse sample of hematological cancer survivors recruited from two different sources as opposed to focussing on only a single hematological cancer type or recruiting patients via treatment centres only. Many participants had already gone through intensive treatment and were currently focussed on the long-term management of their cancer, providing a unique and previously unexplored hematological cancer population. Despite these strengths, the findings of this study should be considered within the limitations of the data and study design. First, adherence was measured using participant selfreport which may over or under-estimate medication adherence compared to other direct and/or indirect measurement methods [10]. However, in the absence of a gold standard, patient self-report is still considered to be the most simple and cost-effective measurement method [10]. Second, as previously noted, clinician monitoring behaviour was also measured via patient self-report rather than direct observation or clinician self-report and as such may be subject to recall bias. Third, the combined study samples recruited via two different methods may limit the generalizability of findings. Given that most participants were more than two years post-diagnosis and currently taking few medications, the results obtained may not be applicable to all hematological cancer patients, particularly those who are more recently diagnosed. Further, the low consent rate of participants recruited from the registry (36 \%) may also affect generalisability of results, however the response rate in the present study is comparable with other studies utilising cancer registries for recruitment $[24,25]$. Finally, the present study only investigated monitoring of adherence by hematologists and regular doctors. Pharmacists are increasingly playing a critical role in managing medication adherence in patients but were not included in the present study [17]. While we attempted to identify whether there were any specific patient characteristics associated with clinician monitoring of adherence, other potential characteristics of clinician behaviour (such as clinician demographics and health care system factors) were not measured. Further research should explore these and other variables to provide a greater understanding of barriers to medication adherence monitoring by clinicians.

\section{Conclusion}

This study has shown that a small but significant proportion of hematological cancer survivors do not adhere to their oral therapy regimen. Missing a dose of one or more medications in the last seven days was the most commonly reported non-adherent behaviour. Despite the serious consequences associated with non-adherence to oral therapy and acknowledgement of the need to provide follow-up support to survivors, the findings presented here indicate that clinicians are not routinely 
monitoring adherence, or at least survivors are not recalling the occurrence of such monitoring. Future research should focus on the development of interventions to support and improve adherence monitoring by cancer clinicians and GPs.

\section{Competing interests}

The authors declare that they have no competing interests.

\section{Authors' contributions}

ML, TCM, AH, RSF, WS \& CT all conceived of the study and contributed to its design and development of measurement tools, ML \& TCM managed the data collection for both studies, ML \& AB performed the statistical analyses, and ML drafted the manuscript. All authors read and approved the final manuscript.

\section{Acknowledgements}

The research conducted in Treatment Centres was supported by a Strategic Research Partnership Grant from the Cancer Council NSW to the Newcastle Cancer Control Collaborative (New-3C), and infrastructure funding from the Hunter Medical Research Institute (HMRI). Dr Tara Clinton-McHarg was supported by a Leukaemia Foundation of Queensland Post-Doctoral Fellowship. The authors would like to thank Dr Heidi Turon for project management, Dr Emilie Cameron for data entry and the staff at the treatment centres for their assistance. The research conducted in the Cancer Registry was supported by a grant (\#569290) awarded through the Priority-driven Collaborative Cancer Research Scheme and co-funded by beyond blue and the Australian Government through Cancer Australia. It also received funding support from a Strategic Research Partnership Grant (CSR 11-02) from Cancer Council NSW to the Newcastle Cancer Control Collaborative (New-3C), and infrastructure funding from the University of Newcastle and Hunter Medical Research Institute. The authors are grateful for all the hard work and assistance of the registry staff, Mrs Sally Whittaker for identification and recruitment of eligible survivors, Ms Sandra Dowley for data entry; Dr Emilie Cameron and Miss Lara Ryan for assistance with data cleaning. The authors would also like to acknowledge the time and effort provided by the cancer survivors who took part in this research, the authors greatly appreciate their involvement, as without their assistance this research would not be possible.

\section{Author details}

${ }^{1}$ School of Medicine and Public Health, Faculty of Health and Medicine, University of Newcastle, Level 4, West, HMRI Building, Callaghan, NSW 2308, Australia. ${ }^{2}$ School of Medicine and Public Health, Faculty of Health and Medicine, The University of Newcastle, 1127 Booth Building, Wallsend Campus, NSW 2308, Australia. ${ }^{3}$ Department of Haematology Royal North Shore Hospital Pathology North, The University of Sydney, Sydney, NSW 2006, Australia. ${ }^{4}$ The Clinical Research Design Information Technology and Statistical Support Unit (CReDITSS), The University of Newcastle, HMRI Building, Callaghan, Sydney, NSW 2308, Australia.

Received: 16 March 2015 Accepted: 4 June 2015

Published online: 11 June 2015

\section{References}

1. Balkrishnan R. The importance of medication adherence in improving chronic-disease related outcomes. What we know and what we need to further know. Med Care. 2005;43(6):517-20.

2. Hohneker J, Shah-Mehta S, Brandt PS. Perspectives on adherence and persistence with oral mediations for cancer treatment. J Oncol Pract. 2011;7(1):65-7.

3. Darkow T, Henk HJ, Thomas SK, Feng W, Baladi JF, Goldberg GA, et al. Treatment interruptions and non-adherence with Imatinib and associated healthcare costs. Pharmacoeconomics. 2007;25(6):481-96.

4. Noens L, van Lierde MA, De Bock R, et al. Prevalence, determinants, and outcomes of nonadherence to imatinib therapy in patients with chronic myeloid leukemia: The ADAGIO study. Blood. 2009;113:5401-11.

5. Marin D, Bazeos A, Mahon FX, Eliasson L, Milojkovic D, Bua M, et al. Adherence is the critical factor for achieving molecular responses in patients with chronic myeloid leukemia who achieve complete cytogenetic responses on imatinib. J Clin Oncol. 2010;28(10):2381-8.
6. Ibrahim AR, Eliasson L, Apperley JF, et al. Poor adherence is the main reason for loss of CCyR and imatinib failure for chronic myeloid leukemia patients on long-term therapy. Blood. 2011;117(4):3733-6.

7. Richardson JL, Shelton DR, Krailo M, Levine AM. The effect of compliance with treatment on survival among patients with hematologic malignancies. J Clin Oncol. 1990;8(2):356-64.

8. National Institute for Clinical Excellence (NICE). Guidance on cancer services improving outcomes in haematological cancers: the manual. London: National Health Service; 2003.

9. Department of Health WA (DOHWA). Haematological Malignancy Model of Care. Perth, WA: Cancer and Palliative Care Network, Department of Health WA; 2009.

10. Osterberg L, Blaschke T. Adherence to Medication. N Engl J Med. 2005;353:487-97

11. Ruddy K, Mayer E, Partridge A. Patient adherence and persistence with oral anticancer treatment. CA Cancer J Clin. 2009:59:56-66.

12. Elwyn G, Edwards A, Britten N. 'Doing prescribing': how doctors can be more effective. Br Med J. 2003;327:864-7.

13. Haynes RB, Ackloo E, Sahota N, McDonald HP, Yao X. Interventions for enhancing medication adherence. Cochrane Database of Systematic Reviews 2008(Issue 2):Art. No.:CD000011.

14. lihara N, Tsukamoto T, Morita S, Myoshi C, Takabatake K, Kurosaki Y. Beliefs of chronically ill Japanese patients that lead to non-intentional nonadherence to medication. J Clin Pharm Ther. 2004;29:417-24.

15. Atkins $L$, Fallowfield L. Intentional and non-intentional non-adherence to medication amongst breast cancer patients. Eur J Cancer. 2006;42:2271-6.

16. Butow P, Palmer S, Pai A, Goodenough B, Luckett $T$, King M. Review of adherence-related issues in adolescents and young adults with cancer. J Clin Oncol. 2010;28(32):4800-9.

17. McCue DA, Lohr LK, Pick AM. Improving adherence to oral cancer therapy in clinical practice. Pharmacotherapy. 2014;34(5):481-94.

18. Australian Bureau of Statisics: Information paper: Outcomes of ABS reviews on remoteness consultation, Australia. In. Edited by ABS. Canberra: ABS; 2001

19. Evans J, Ziebland S, Pettitt AR. Incurable, invisible and inconclusive: watchful waiting for chronic lymphocytic leukaemia and implications for doctorpatient communication. Eur J Cancer Care. 2012;21:67-77.

20. O'Brien SG, Guilhot F, Larson RA, et al. Imatinib compared with interferon and low-dose cytarabine for newly diagnosed chronic-phase chronic myeloid leukemia. N Engl J Med. 2003;348:994-1004.

21. Burnier M. Long-term compliance with antihypertensive therapy: another facet of chronotherapeutics in hypertension. Blood Pressure Monitoring. 2000;5(Supple 1):S31-4.

22. Horne R, Weinman J. Patients' beliefs about prescribed medicines and their role in adherence to treatment in chronic physical illness. J Psychosom Res. 1999:47(6):555-67.

23. Fink AK, Gurwitz J, Rakowski W, et al. Patient beliefs and tamoxifen discontinuance in older women with estrogen receptor-positive breast cancer. J Clin Oncol. 2004;22:3309-15.

24. Boyes AW, Girgis A, D'Este C, Zucca A. Prevalence and correlates of cancer survivors' supportive care needs 6 months after diagnosis: A populationbased cross-sectional study. BMC Cancer 2012, 12(150).

25. Smith T, Stein KD, Mehta CC, Kaw C, Kepner JL, Buskirk T, et al. The rationale, design and implementation of the American Cancer Society's studies of cancer survivors. Cancer. 2007;109:1-12.

\section{Submit your next manuscript to BioMed Central and take full advantage of:}

- Convenient online submission

- Thorough peer review

- No space constraints or color figure charges

- Immediate publication on acceptance

- Inclusion in PubMed, CAS, Scopus and Google Scholar

- Research which is freely available for redistribution 